\title{
Promotion of Safe Work Practices in the Agricultural Sector through Coaching as a Training Strategy in
}

\section{Australia}

\author{
Richard Skiba ${ }^{1, *}$ \\ ${ }^{1}$ LRES Training Management, Melbourne, Australia \\ *Corresponding author: LRES Training Management, Melbourne, Australia. Tel: \\ 61-4-04-043013. E-mail: richard@skiba.com.au
}

Received: April 30, 2020 Accepted: July 26, 2020 Published: September 25, 2020

doi:10.5296/ije.v12i3.16938 URL: https://doi.org/10.5296/ije.v12i3.16938

\begin{abstract}
There is currently, and historically, a high rate of workplace incidents and fatalities in the Australian Agricultural sector. This paper considers the use of coaching as a mechanism for provision of best practice safety training and development of a safety culture in Agricultural work places, particularly based on the current industry profiles and preferred methods of workplace learning. Current studies, including Safe Work Australia and AgHealth Australia data, and literature, such as Krauesslar and Passmore (2015) and Somes (2018), are reviewed to explain how coaching can enable workers to feel motivated and involved in workplace safety, and in effect, reducing the incidence of workplace injuries and fatalities. As such, the paper considers 'what is the most successful training method to develop a stronger health and safety culture in the Agricultural Sector?'

The discussion finds that the most commonly and most effective learning approaches utilized in agricultural settings are based on 'farmers learning from farmers'. This is effectively a coaching approach, and in turn, workplace coaching should be considered as a generic foundation skill taught to all workers in Agriculture to encourage effective consultation practices and communication between workers. The development of coaching skills can occur through their inclusion in formal training programs, such Certificate III or IV level programs in Vocational Education and Training and through short specific targeted programs.
\end{abstract}

Keywords: vocational education and training, health and safety, coaching, training practices, adult learning 


\section{Mll Macrothink}

\section{Introduction}

Safe Work Australia publishes many studies that provide details on the circumstances of work-related accidents in Australia (Safe Work Australia, 2019a). The work-related traumatic injury fatalities report includes information on people who die each year from accidents caused by work-related activity. It includes deaths that occur from an accident suffered in the course of a work operation (worker fatality) and as a result of someone else's work operation (bystander fatality). As at 21 November, 2019, there were 144 Australian workers killed at work in 2019. In 2018, 144 Australian workers were fatally injured, compared with 189 workers in 2017.

The Safe Work Preliminary worker deaths by industry of workplace, Year-to-date 2019 (November 2019), outline that 30 of the 144 reported fatalities occurred in the Agriculture, Forestry and Fishing industries, representing approximately $20.8 \%$ of the total. Safe Work Australia (2019a) indicates that this industry is second only to the Transport, Postal and Warehousing industry, with $37.5 \%$ of the fatalities, and followed by the Construction industry with $14.5 \%$. Safe Work Australia (2019a) outlines fatality numbers as shown in table 1.

Table 1. Preliminary Worker Deaths by Industry of Workplace, Year-to-date 2019 (November 2019)

\begin{tabular}{lll}
\hline Industry of workplace & $\begin{array}{l}\text { Preliminary worker } \\
\text { deaths year-to-date, } 21\end{array}$ & $\begin{array}{l}\text { Preliminary worker deaths } \\
\text { year-to-date, 21 November } \\
\text { November 2018 }\end{array}$ \\
& 40 & 2019 \\
\hline Transport, postal \& warehousing & 32 & 54 \\
Agriculture, forestry \& fishing & 25 & 30 \\
Construction & 9 & 21 \\
Mining & 3 & 8 \\
Electricity, gas, water \& waste services & 9 & 6 \\
Manufacturing & 4 & 6 \\
Public administration \& safety & 0 & 6 \\
Other services & 1 & 5 \\
Arts \& recreation services & 2 & 3 \\
Wholesale trade & 0 & 2 \\
Professional, scientific \& technical services & 1 & 2 \\
Administrative \& support services & 1 & 1 \\
Health care \& social assistance & 1 & 0 \\
Retail trade & 1 & 0 \\
Rental, hiring \& real estate services & 0 & 0 \\
Accommodation \& food services & 0 & 0 \\
Education \& training & 0 & 0 \\
Financial \& insurance services & 0 & 0 \\
Information media \& telecommunications & 129 & 0 \\
Total worker deaths & & 144 \\
\hline
\end{tabular}




\section{Macrothink}

The fatality and injury statistics, as noted by Safe Work Australia (2018), identify priority industries. These are industries that have high numbers and rates of fatalities and/or injuries or are inherently hazardous. The identified industries are:

- Agriculture

- Road transport

- Manufacturing

- Construction

- Accommodation and food services

- Public administration and safety, and

- Health care and social assistance.

The five year average fatality rates for Agriculture (13.8 fatalities per 100,000 workers), Road Transport (13.5 fatalities per 100,000 workers) and Construction (2.9 fatalities per 100,000 workers) sit well above the rates for the remaining priority industries, as well as the fatality rate across all industries ( 1.5 fatalities per 100,000 workers). Table 3 outlines the fatality rates as identified by Safe Work Australia. (2019c) for a range of industries.

Table 2. Worker Fatalities - Number of Fatalities and Fatality Rate by Industry of Employer, 2018

\begin{tabular}{lll}
\hline Industry of employer & Number of fatalities & $\begin{array}{l}\text { Fatality rate (fatalities } \\
\text { per } 100 \text { 000 workers) }\end{array}$ \\
\hline Agriculture, forestry \& fishing & 37 & 11.2 \\
Transport, postal \& warehousing & 38 & 5.9 \\
Mining & 9 & 3.7 \\
Construction & 24 & 2.0 \\
Electricity, gas, water \& waste services & 3 & 2.0 \\
Manufacturing & 13 & 1.4 \\
Wholesale trade & 3 & 0.8 \\
Rental, hiring \& real estate services & 2 & 0.9 \\
Information media \& telecommunications & 2 & 0.9 \\
Arts \& recreation services & 2 & 0.8 \\
Administrative \& support services & 3 & 0.7 \\
Other services & 2 & 0.4 \\
Public administration \& safety & 3 & 0.4 \\
Accommodation \& food services & 1 & 0.1 \\
Education \& training & 1 & 0.1 \\
Health care \& social assistance & 1 & 0.1 \\
Retail trade & 0 & 0.0 \\
Professional, scientific \& technical services & 0 & 0.0 \\
Financial \& insurance services & 0 & 0.0 \\
Total & 144 & 1.1 \\
\hline
\end{tabular}


AgHealth Australia (2019) reports that there were 67 non-fatal on-farm injuries reported in the Australian media from 1 January to 30 June 2019. Of these, nine (13.4 percent) of the 67 injury events involved children aged under 15 years. Quad bike-related injuries accounted for over $20 \%$ of all incidents, followed by horse-related incidents $(n=10)$, utility vehicle-related incidents $(n=7)$ and tractor-related incidents $(n=6)$.

These figures and others, supported by The Land (2018), raise concerns about the degree of awareness of farm safety in general, the amount of resources, including time, that farm owners are willing to put into farm safety, as well as the awareness of the business owner of their responsibilities. They also consider that the agricultural incident and fatality statistics raise questions as to how aware employees may or may not be of risks in their workplace.

Given the high-risk nature of agricultural work, special consideration must be given to any means of hazard control and risk minimization and this study outlines an approach focusing on training practices.

\section{Method}

The discussion and conclusions drawn are based on a literature review together with consideration of the current practices in training and assessment of health and safety components in the Agricultural Sector. This paper outlines the use of on the job coaching to promote health and safety knowledge and skills, and their application in the workplace. The discussion firstly establishes the need for consideration of current practices and outcomes of improved practices and then aims to establish how these needs can be addressed. The creation of coaching skills is also explored through discussions about how such skills can be developed.

\section{Discussion}

\subsection{Agricultural Worker Profile}

In order to profile a representative agricultural worker, two roles will be considered - Crop Farmers and Livestock Farmers. Job vacancy demand data identified by the Australian Industry and Skills Commission (2019) for the agricultural industry suggests that communication skills followed by physical demand are the top generic skills needed by employers. Mixed Crop and Livestock Farm Workers were the highest occupation in demand. Using the ABS Census 2016 data, Job Outlook (2019a, b) outlines the general characteristics of these workers. The Crop Farmer cohort average age is 52 years and many workers are 45 years or older $(67 \%)$. The majority, 33.2\% have completed Year 10 and below followed by approximately $18 \%$ having completed Year 12 and the same proportion having attained a Certificate III or Certificate IV level qualification.

For Livestock Farmers, the average age is 57 years and many workers are 45 years or older (76\%). Within this grouping, a broad range of educational qualifications have been completed. 


\section{Ml Macrothink}

The highest portion, 34.5\% have completed Year 10 and below, followed by a significant proportion, 19\%, having completed a Certificate III or Certificate IV level qualifications. Approximately 10\% have completed a Diploma or Advanced Diploma level qualification and likewise, approximately $10 \%$ have completed a Bachelor Degree program.

This data indicates that the majority of workers in crop and livestock farming have had no formal agricultural training. For those that have, the VET sector is the most commonly accessed training sector.

All industries have general workplace or occupational health and safety laws, but the agricultural industry also has state-specific health and safety requirements, including:

- control of noise at work

- protective clothing and equipment

- safety signage

- manual handling

- quad bike safety practices

- electrical safety practices

- hay bale safety practices

- animal handling

- biosecurity measures

The significant number of workers in the Agricultural Sector gain an understanding of these requirements and practices on the job. For Crop Farmers, 59.9\% having completed secondary education with no further formal training specific to the industry and for Livestock farmers, $57.6 \%$ having completed secondary education with no further formal training specific to the industry. The on the job learning relies on effective communication and coaching.

Safe Work Australia (2018b) in summarizing worker fatalities numbers by age group, 2014 to 2018 outline that for that period, the highest number of fatalities, at $22.3 \%$ occurs in the 55 to 64 year old age group, followed by the 45 to 54 year old age group, at $21.2 \%$. The average age of Crop Farmers at 52 years old and Livestock Farmers at 57 years old places these two groups of workers as significantly at risk of workplace incidents. Safe Work Australia (2019b) worker fatality number by age are summarized as table 2 .

Table 3. Worker Fatalities: Number by Age Group, 2014 to 2018

\begin{tabular}{lllllll}
\hline Age group & 2014 & 2015 & 2016 & 2017 & 2018 & 5 year total (2014-2018) \\
\hline Under 25 & 22 & 17 & 16 & 16 & 19 & 90 \\
$25-34$ & 33 & 39 & 33 & 32 & 24 & 161 \\
$35-44$ & 28 & 28 & 24 & 33 & 25 & 138 \\
$45-54$ & 45 & 50 & 39 & 36 & 27 & 197 \\
$55-64$ & 38 & 42 & 48 & 48 & 31 & 207 \\
65 \& over & 31 & 36 & 26 & 24 & 18 & 135 \\
Total & 197 & 212 & 186 & 189 & 144 & 928 \\
\hline
\end{tabular}




\section{Macrothink

Safe Work Australia (2019b) outlines that workers between 45 and 54 years of age accounted for the largest number of deaths (820) over the last 16 years and further note that in 2018:

- $35 \%(51)$ of workers killed were engaged as machinery operators and drivers

- $25 \%$ (36) of workers killed were labourers

- 19\% (27) of workers killed were technicians and trades workers

- $11 \%(16)$ of workers killed were mangers.

indicating a significant need for health and safety training as a focus in machinery operation, such as heavy vehicle, mobile plant and agricultural equipment.

\subsection{Employer Obligations for Health and Safety Training}

There is a legal obligation to provide training in the area of health and safety at work in order to continue to meet the duty of care requirements for the health, safety and wellbeing of employees (Australian Business and Consultation Solutions, 2019).

This is contained in the main Workplace Health and Safety (WHS)/Occupational Health and Safety (OHS) Act in each state of Australia and includes:

- induction and safety preparation of new employees in the workplace

- train workers for the specific workplace tasks they will have to perform

- commit to appropriate supervision and monitoring of workers

- support regular refresher training.

There are also specific safety training standards and requirements, which are laid down in the relevant provisions of the Law. In addition to these specific training requirements, there could be other things that employers may need to train their workers, such as emergency evacuation protocols, machine and device service, general safety induction, work station ergonomic training, chemical awareness, risk evaluation and accident investigation.

Workplace health and safety training can include both formal and informal training. Safe Work Australia (1996) outlines that there are essentially four types of health and safety training courses available:

- licence or certificate courses

- accredited and approved courses

- short courses

- vocational and professional courses

Most health and safety training is provided by:

- employers

- unions

- the health and safety organisations (either State or Territory or the Commonwealth)

- Technical and Further Education (TAFE) providers and universities 
- private occupational health and safety consultants/trainers

Many employers send their supervisors to these organisations for training. Training can also be provided in-house by these organisations. Given the diverse range of training programs and providers, there may be significant differences in the quality of training with minimum consistency.

Most training courses are defined as competency based. In a competency-based training (CBT) program, people develop the skills and knowledge they need to be able to carry out their work. The CBT systems are focused on what people at work are supposed to do and the performance expectations in the workplace.

Knowledge development is essential in a competency based program. It is equally necessary to be able to apply the knowledge at work. The VET system is based on a Competency Based model and promotes national consistency in standards, delivery and assessment. Competency specifications for Nationally recognised programs are maintained in training.gov.au. Training.gov.au is the National Register of Vocational Education and Training (VET) in Australia and is the primary and authoritative source of Nationally Recognized Training (NRT) consisting of Training Packages, Qualifications, Competence Levels, Accredited Courses and Skill Sets (Department of Employment, Skills, Small and Family Business, 2016).

\subsection{Training Options}

Somes (2018) quotes AgSkilled Coordinator Claudia Vicary with "The key responsibility for farm safety rests primarily with individual farmers, farm families and farm workers, so we need to improve their knowledge, understanding and implementation of practical safety solutions to reduce the risk of death, injury and illness", noting the need for training and development in addressing safety issues in the Agricultural sector. People in Agriculture (2019) advise that there are many different ways training can be conducted, which may be internal or external to the organization. Training may be provided by experienced staff with specialized knowledge or more informally through coaching or extension programs. They also note that coaching is an extremely useful, but often neglected, process for developing skills and is probably most relevant to on-site training.

In this sense, coaching focuses on modifying behaviors in order to meet the minimum expectations required on the farm. It includes helping workers take on new ways of doing things or different tasks, which needs continuous communication between the learner and the coach.

Greenhalgh and Rawlinson (2014), citing A.N. Scholz \& Associates Inc and Qu'anglo Communications \& Consulting 2012, p. 1, outline that Farmers prefer working with each other, either one-to-one, in organized small groups or as clubs that are led and managed by professional facilitators or advisors'. Such an environment is characterized by coaching or mentoring approaches, and on this basis, these can be seen as the preferred approach to training in the Agricultural sector. The coach's role is to build on the individual's existing skills and to motivate workers to try something new, including undertaking work tasks in new 
ways.

Extension activities can be as basic as field days, professional development seminars or knowledge awareness-raising discussion groups (People in Agriculture, 2019). The benefits of the extension programs include having an opportunity to keep up with current information and technology and a way to stay in contact with the social network for information gathering, being able to catch up and discuss issues with other farmers. Many work aspects, such as first aid training or licences for specialized equipment, require approved instruction through accredited training and would need to be performed by professional trainers who are typically employed by a Registered Training Organization (RTO) and cannot be handled internally in the workplace. Use of agricultural equipment is not currently covered by licencing arrangements.

\subsection{Effective Coaching for Safety Training}

Krauesslar and Passmore (2015) describe that one particular method of coaching, which they define as safety coaching, is the technique of watching, inspiring and promoting safety performance. They further note that behavioral based safety coaching can be defined as a process of observation and feedback providing support for safe behaviors and constructive feedback on risky workplace behaviors. Krauesslar et al. (2015) advocate that coaching can be used to encourage healthy working practices and foster an understanding of safety issues.

Coaching can further be categorized as skills, performance or developmental coaching (Grant, Passmore, Cavanagh, and Parker, 2010). They define skills' coaching as focusing on developing a specific, designated skill set, performance coaching concerned with improving performance over a specific timeframe, and developmental coaching taking a broader strategic approach and dealing with the individual's personal and professional development. Safety coaching, as defined by Krauesslar and Passmore (2015), can form the basis of each of the categories defined by Grant et al. (2010) and can serve to fulfil a range of objectives. As such, safety coaching can be utilized to encourage general safety knowledge, such as recognition of what is dangerous or hazardous in the workplace and determining what is highest risk and needs to be addressed first, and how to go about fixing it.

Likewise, safety coaching can contribute to organizational induction and training, covering aspects such as contributing to ensuring experienced workers are involved in any training, assessing competence of workers, reviewing training needs, ensuring all workers are aware of the accepted safe work procedures and planning an approach before starting activities (Workcover Queensland, 2018). These are critical activities for fostering an effective health and safety culture. Further, Worklogic (2019) believe coaching enhances individual and organizational health through transition, and encourages development, confidence and innovation. They also outline that coaching promotes collaboration, engagement and dedication and leads to risk management and prevention of workplace disharmony.

In order for coaching to be implemented effectively and utilized more commonly, development of coaching and mentoring skills needs to be incorporated into formal training programs in agriculture. Incorporating both the practice and theory of mentoring in 
agricultural training at vocational and university levels is a means of both raising awareness and developing an industry culture in favour of mentoring (Greenhalgh and Rawlinson, 2014).

Safe Work Australia (2013) advise that Farmers will be most active when the information imparted is of immediate and realistic value to them. Further, Farmers are more likely to become interested when the training / information is given in areas where they are already gathered, for example, at field days, selling yards or local meetings. These notions support the use of mentoring and coaching as a significant safety training tool in Agricultural work places. Safe Work Australia (2013) also note that Farmers have a preference to be trained by other farmers who are specialists in health and safety rather than by generic health and safety specialists.

Dr Anna Blackman from JCU's College of Business, Law \& Governance, referred to in James Cook University (2019), states business coaching techniques could cut the death and injury rate of farmers. Dr Blackman explains coaching is different from mentoring and requires more than a one-day course. She contrasts mentoring and coaching by differentiating that mentoring is based on the technical aspects of a task or role and course material sometimes ends up in a desk drawer and is never looked at again. Coaching, on the other hand, is ongoing and occurs over a period of months, and tries to get the person being coached to think about how they could drive change themselves.

James Cook University (2019) further explains that the coaching model had repeatedly proven effective in improving profitability, performance and communication in businesses it was applied to, and it was likely it could be used to enhance farm safety as well, as provided by Dr Blackman.

It will take time to develop a culture within the industry where coaching is seen as a valuable process and younger farmers will recognise the potential it has for enhancing their learning, and thus seek out mentorship. This would be helped if teaching about the concept of coaching was embedded in all formal agricultural training and educational programs.

\subsection{Workplace Coaches}

A coach is someone who works one-on-one with an individual or with a team to help them unlock their maximum potential (Directions Unlimited, 2019). In a workplace environment, including those in an agricultural setting, a coach helps individuals achieve their professional outcomes while still holding them accountable for their work. This entails provision of non-judgmental support, ensuring the welfare of their coachee is met, both at work and outside of work. Developing coaching in workplace training is the best way to create a coaching culture. There are a number of skills and knowledge that need to be imparted into individuals to become effective workplace coaches. These centre around communication skills, prioritizing employee engagement and fostering an environment of trust.

Irrespective of training undertaken in agriculture, whether through formal vocational education and training, professional development activities, regulator or local governance programs or any number of informal training activities, inclusion of coaching skills is a 
critical factor in promoting the coaching culture. A workplace environment in which managers trust their employees and employees trust their managers is one where productivity and safety can thrive.

McCarthy and Ahrens (2012) say that short training programs tend to be effective in equipping managers with basic coaching skills such as listening, questioning, goal-setting and feedback, but may be less suitable for teasing out the nuances of the role of manager as coach and for learning how to coach teams. They also say that, at present, it seems that many managers in Australia have had minimal coaching training but have extended their range of models and strategies by self-directed learning and using in coaching what they have learned in other contexts.

\subsection{Training for Coaching}

In order to facilitate knowledge sharing training providers could integrate aspects of coaching skills and knowledge into their training programs. In Vocational Education and Training this may mean overtly adding development of these skills and knowledge into their training and assessment strategies to embed them as standard training practices to be implemented by their trainers. As macro areas, this includes development of listening and questioning skills, skills to build rapport, ways to empathize with others, abilities to summarize and reflect, methods to provide and receive feedback and ways to remain open-minded and judgmental. Research by Milner and Milner (2018) considers how people can be trained to be better coaches. They listed nine leadership coaching skills, based on current literature and their own practical coaching experience, including:

- listening

- questioning

- giving feedback

- assisting with setting goals

- showing empathy

- allowing the coachee to come to their own solution

- recognizing and highlighting strengths

- providing structure

- encouraging a solution-focused approach

Aspects of these macro areas can be integrated into assessment task, whether formative or summative to ensure that they are imparted to participants in formal training programs. Irrespective of how development of these areas are added to training and assessment activities, they should allow time for participants to reflect on their coaching abilities. The most important characteristic of any coach is that they want to help the person or people they're coaching to learn.

As an example of putting this approach into practice, assessment activities can be structured to require providing coaching including using interpersonal skills to:

- build rapport, trust and respect with individual

- facilitate identifying the individual's development goals 
- facilitate identifying solutions and actions

- encourage and support the individual to develop towards the achievement of goals

- assist the individual to make decisions about achieving goals

This assessment approach can be integrated into any number of units of competency applicable to agriculture, whether they be AHCWHS301 Contribute to work health and safety processes, at a Certificate III level, through to AHCLSK401 Develop feeding plans for a production system, for example, at a Certificate IV level.

Currently, there is not an AHC based skills set focusing on coaching skills targeted at agricultural workers, however training providers can also develop formal and informal training programs to train participants in coaching skills.

Participants who develop these skills will be able to more effectively contribute to their workplace safety culture in that they will have the capacity to impart their knowledge and skills to their colleagues, many of which have not had formal training in the agricultural sector.

\section{Recommendations and Conclusions}

There is an identified health and safety issue in the Agricultural sector based on the number of reported injuries and fatalities. A means to reduce and prevent further incidents is through worker training such that they are aware of safety issues and can learn to apply safe work practices. The majority of learning in the sector takes place on the job, and the preferred means of training, and learning, is through workplace coaching. In order for workplace coaching to be effective in creating a safety culture, workers need to develop the required skills to provide coaching to their colleagues. During the design phases of program development, training providers in the Vocational Education and Training system should ensure that the programs they aim to deliver not only address technical and operational skills and knowledge but also the ability to share skills and knowledge with other workers through coaching. The intention of any training and assessment process in Vocational Education and Training is to provide the participant with the ability to undertake their work roles in a safe manner. This is particularly the case for high risk occupations such as those seen in the Agricultural sector.

\section{References}

AgHealth Australia. (2019). Australian Farm Deaths \& Injuries Media Monitors Snapshot January $1-$ June 30, 2019. Retrieved April 30, 2020 from https://aghealth.sydney.edu.au/wp-content/uploads/2019/09/Farm-Related-Injuries-JunReport-2019.pdf

Australian Business and Consultation Solutions. (2019). Meeting the training needs of your $\begin{array}{lllll}\text { employees. } & \text { Retrieved } & \text { April } & & \\ & & \end{array}$ 
http://www.australianbusiness.com.au/whs/resources/meeting-the-training-needs-of-your -employees

Australian Industry and Skills Commission. (2019). Agriculture. Retrieved April 30, 2020 from https://nationalindustryinsights.aisc.net.au/industries/agriculture

Department of Employment, Skills, Small and Family Business. (2016). About training.gov.au. Retrieved April 30, 2020 from https://training.gov.au/Home/About

Department of Employment, Skills, Small and Family Business. (2019a). Crop Farmers. $\begin{array}{llll}\text { Retrieved April } & 30, & 2020 & \text { from }\end{array}$ https://joboutlook.gov.au/Occupation?search=Career\& code $=1212$

Department of Employment, Skills, Small and Family Business. (2019b). Livestock Farmers. $\begin{array}{lllll}\text { Retrieved } & \text { April } & 30, & 2020 & \text { from }\end{array}$ https://joboutlook.gov.au/Occupation?search=Career\&code $=1212$

Directions Unlimited. (2019). How to create a coaching culture in your workplace. Retrieved $\begin{array}{llll}\text { from } & \text { April 30, } 2020\end{array}$ https://www.directionsunlimited.com.au/coaching/create-coaching-culture-workplace/

Grant, A. M., Passmore, J., Cavanagh, M. J., \& Parker, H. (2010). The State of Play in Coaching Today: A Comprehensive Review of the Field. Annual Review of Industrial \& Organizational Psychology. Chichester: Wiley. https://doi.org/10.1002/9780470661628.ch4

Greenhalgh, J., \& Rawlinson, P. (2014). A review of mentoring in agriculture: Another learning option for the next generation of New Zealand farmers? Extension Farming Systems Journal, 9(1), 1-9.

James Cook University. (2015). New approach to farm safety. Retrieved April 30, 2020 from https://www.jcu.edu.au/news/releases/2015/april/news-and-media

Krauesslar, V., Avery, R., \& Passmore, J. (2015). Taking Ownership of Safety. International Journal of Occupational Safety and Ergonomics, 21(1), 39-46 http://dx.doi.org/10.1080/10803548.2015.1017941

McCarthy, G., \& Ahrens, J. (2012). How and why do managers use coaching skills? In G. Heaslip \& R. Galavan (Eds.), Proceedings of the Irish Academy of Management Conference 2012 Ireland: Irish Academy of Management.

Milner, J., \& Milner, T. (2018). Most Managers Don't Know How to Coach People. But They Can Learn. Harvard Business Review. Retrieved April 30, 2020 from https://hbr.org/2018/08/most-managers-dont-know-how-to-coach-people-but-they-can-le arn

People in Agriculture. (2019). Professional Development and Performance Appraisals. $\begin{array}{llll}\text { Retrieved April } & \text { 30, } & 2020 & \text { from }\end{array}$ https://www.peopleinag.com.au/farming/employers/workplace-training-and-developmen 
t/professional-development-and-performance-appraisals/

Safe Work Australia. (1996). Organising Health and Safety Training for your Workplace. Australian Government Publishing Service, Canberra.

Safe Work Australia. (2013). Work-related injuries and fatalities on Australian farms. Safe Work Australia, Canberra.

Safe Work Australia. (2018a). Work-related Traumatic Injury Fatalities, Australia: 2018. Safe Work Australia.

Safe Work Australia. (2018b). Australian Work Health and Safety Strategy 2012-2022. $\begin{array}{llll}\text { Retrieved April 30, } & \text { Arom }\end{array}$ https://www.safeworkaustralia.gov.au/book/australian-work-health-and-safety-strategy-2 $012-2022$

Safe Work Australia. (2019a). Fatality statistics. Retrieved April 30, 2020 from https://www.safeworkaustralia.gov.au/statistics-and-research/statistics/fatalities/fatality-s tatistics

Safe Work Australia. (2019b). Fatality statistics by age. Retrieved April 30, 2020 from https://www.safeworkaustralia.gov.au/statistics-and-research/statistics/fatalities/fatality-s tatistics-age

Safe Work Australia. (2019c). Fatality statistics by industry. Retrieved April 30, 2020 from https://www.safeworkaustralia.gov.au/statistics-and-research/statistics/fatalities/fatality-s tatistics-age

Somes, T. (2018). Innovative training has key role in improving farm safety. Grains Research \& Development Corporation. Retrieved April 30, 2020 from https://grdc.com.au/news-and-media/news-and-media-releases/north/2018/07/innovative -training-has-key-role-in-improving-farm-safety

The Land. (2018). No change in fatality rate in 15 years highlights importance. Retrieved from April 30, 2020 https://www.theland.com.au/story/5159243/time-to-improve-the-stats-on-farm-safety/

Workcover Queensland. (2018). Health and safety tips for the agriculture, forestry and fishing $\begin{array}{lllll}\text { industry. } & \text { Retrieved } & \text { April } & 30, & \end{array}$ from https://www.worksafe.qld.gov.au/agriculture/health-and-wellbeing-at-work/health-and-s afety-tips-for-the-agriculture,-forestry-and-fishing-industry

Worklogic. (2019). Coaching to help your employees and leaders maximise their capability and effectiveness and minimise people-risk. Retrieved April 30, 2020 from https://www.worklogic.com.au/services/coaching/ 


\section{Copyright Disclaimer}

Copyright for this article is retained by the author(s), with first publication rights granted to the journal.

This is an open-access article distributed under the terms and conditions of the Creative Commons Attribution license (http://creativecommons.org/licenses/by/3.0/). 